\title{
Mempertahankan Kinerja Karyawan di Masa Pandemi Covid-19: Studi Kasus pada Industri Ritel
}

\author{
Masduki Asbari ${ }^{1}$, Dewiana Novitasari ${ }^{2}$, Francisca Sestri \\ Goestjahjanti ${ }^{3}$ \\ Sekolah Tinggi Ilmu Ekonomi Insan Pembangunan \\ kangmasduki.ssi@gmail.com
}

\begin{abstract}
This study aimed to measure the effect of transformational leadership on employee performance of the employee of a retail industry in West Java which are mediated by readiness for change. Data collection during covid-19 pandemic was done by simple random sampling technique and the returned and valid questionnaire results were 214 samples. Data processing was used SEM method with SmartPLS 3.0 software. The results of this study concluded that transformational leadership have not significant effect on the employee performance, but transformational leadership have a positive and significant effect on readiness for change. This study conclude also that readiness for change have a positive and significant effect on relationship between transformational leadership and employee performance. Readiness for change as fully mediator. This new research proposed a model for building employee performance among the employee of a retail industry in West Java through enhancing transformational leadership practice with readiness for change as a mediator. This research could pave the way to improve employee readiness in facing the era of industrial revolution 4.0.
\end{abstract}

Keywords: Employee performance, readiness for change, transformational leadership.

\begin{abstract}
Abstrak
Penelitian ini bertujuan untuk mengukur pengaruh kepemimpinan transformasional terhadap kinerja karyawan karyawan industri ritel di Jawa Barat yang dimediasi oleh kesiapan untuk berubah. Pengumpulan data dilakukan selama masa pandemic Covid-19 dengan teknik simple random sampling dan hasil kuesioner yang kembali dan valid adalah 214 sampel..Pemrosesan data menggunakan metode SEM dengan perangkat lunak SmartPLS 3.0. Hasil penelitian ini menyimpulkan bahwa kepemimpinan transformasional tidak berpengaruh signifikan terhadap kinerja karyawan, tetapi kepemimpinan transformasional berpengaruh positif dan signifikan terhadap kesiapan untuk berubah. Penelitian ini menyimpulkan juga bahwa kesiapan untuk berubah memiliki pengaruh positif dan signifikan terhadap hubungan antara kepemimpinan transformasional dan kinerja karyawan. Kesiapan untuk berubah sebagai mediator sepenuhnya. Penelitian baru ini mengusulkan model untuk membangun kinerja karyawan di antara karyawan industri ritail di Jawa Barat melalui peningkatan praktik kepemimpinan transformasional dengan kesiapan untuk berubah sebagai mediator. Penelitian ini dapat membuka jalan untuk meningkatkan kesiapan karyawan dalam menghadapi era revolusi industri 4.0.
\end{abstract}

Kata kunci: Kepemimpinan transformasional, kesiapan untuk berubah, kinerja karyawan. 


\begin{tabular}{lrl}
\hline Permalink/DOI & $:$ & http://dx.doi.org/10.32503/jmk.v5i2.1000 \\
Cara Mengutip & $:$ & Asbari, Masduki., dkk. (2020). Mempertahankan Kinerja \\
& Karyawan di Masa Pandemi Covid-19: Studi Kasus pada \\
& Industri Ritel. JMK (Jurnal Manajemen dan Kewirausahaan), 5 \\
& (3), 183-203 doi: http://dx.doi.org/10.32503/jmk.v5i3.1093 \\
Sejarah Artikel $:$ & Artikel diterima 10 Juli 2020; direvisi 19 Juli 2020; disetujui 27 \\
& Juli 2020 \\
\hline
\end{tabular}

\section{Pendahuluan}

Di era revolusi industri 4.0, bagi sebagian besar perusahaan, perubahan dramatis merupakan fenomena yang mutlak dan tidak bisa dihindari. Perusahaan harus mempunyai strategi yang mampu melakukan transformasi dan inovasi untuk menghadapinya. Ini agar perusahaan dan bisnis yang telah dibangun tidak tergilas oleh zaman dan terhambat perkembangannya (Agistiawati et al., 2020; Asbari, 2015; Jumiran et al., 2020; Novitasari et al., 2020; Nuryanti et al., 2020; Sudiyono et al., 2020; Yuwono et al., 2020). Perusahaan harus sudah memiliki sebuah peta perjalanan yang terintegrasi sehingga arah pengembangan bisnis terlihat dengan jelas. Di antara strategi yang mendesak untuk diperhatikan adalah kesiapan untuk berubah (readiness for change) pada diri setiap organisasi, lebih-lebih pada organisasi bisnis global. Kompetisi global era kini meniscayakan kesiapan untuk berubah tanpa jeda dari setiap insan insan industry. Kondisi pandemi covid-19 yang sedang melanda dunia, tak terkecuali Indonesia, meniscayakan perubahan situasi dan kondisi bisnis mutakhir (Purwanto, Asbari, Fahlevi, et al., 2020b; Purwanto, Pramono, Asbari, et al., 2020f;
Setyowati Putri et al., 2020). Oleh karena itu, manajemen wajib melakukan langkah-langkah praktis dan strategis untuk membawa organisasi keluar dari kubangan krisis yang nyaris menenggelamkan sebagian perusahaan yang tidak menyiapkan diri dengan baik.

Tak dapat dipungkiri, bahwa masyarakat Indonesia memiliki semangat patronasi yang kuat. Oleh karena itu, memperhatikan praktek kepemimpinan pada setiap unit sosial masyarakat, apalagi pada organsiasi bisnis menjadi penting dan genting (Asbari, Chi Hyun, Wijayanti, et al., 2020; Asbari, Hyun, Wijayanti, et al., 2020; Asbari, Pramono, Kotamena, et al., 2020; Asbari, Purwanto, Fayzhall, et al., 2020; Asbari, Purwanto, Maesaroh, et al., 2020; Asbari, Wijayanti, et al., 2019; Asbari, Wijayanti, Hyun, et al., 2020; Fikri et al., 2020; Sopa et al., 2020a, 2020b). Walaupun demikian, di lapangan penelitian ditemukan bahwa praktek kepemimpinan transformasional tidak memberikan pengaruh signifikan terhadap kinerja karyawan, sebagaimana beberapa penelitian berikut ini: (David et al., 2017; Eliyana et al., 2019; Khalifa Elgelal \& Noermijati, 2014; Makena, 2017; Monoyasa et al., 2017; Putri \& Soedarsono, 2017; Siswatiningsih 
et al., 2019). Berbeda dengan beberapa penelitian mapan lainnya yang menyebutkan bahwa kepemimpinan transformasional berpengaruh signifikan terhadap kinerja karyawan (Asbari, 2019; Fayzhall, Asbari, Purwanto, Goestjahjanti, et al., 2020; Jumiran et al., 2020; Maesaroh et al., 2020; Nugroho et al., 2020; Waruwu et al., 2020; Yanthy et al., 2020). Sehubungan masih ada terjadi research gap di dalam hubungan antara kepemimpinan transformasional, kesiapan untuk berubah dan kinerja karyawan, maka penelitian ini dipandang perlu untuk dilakukan. Misalnya, penelitian (Mahessa \& NRH, 2016) yang menyebutkan bahwa kepemimpinan berpengarauh positif dan significant terhadap kesiapan untuk berubah, sedangkan penelitian (Susyanto, 2019) secara berbeda menemukan bukti bahwa kepemimpinan transformasional tidak memiliki pengaruh signifikan terhadap kesiapan untuk berubah pada karyawan. Oleh karena itu, research gap ini mendorong peneliti untuk mengelaborasi lebih dalam dan meluas tentang hubungan kedua konstruk tersebut.

\section{Tinjauan Pustaka}

\section{Kepemimpinan Transformasional}

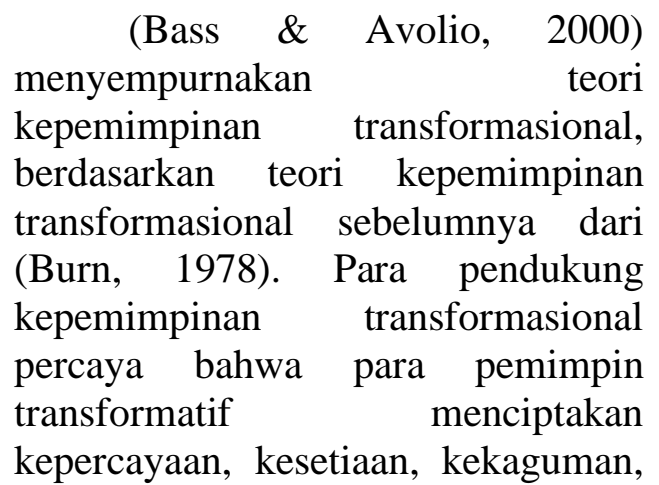

dan rasa hormat di antara para pengikut, dan di antara para pengikut dan para pemimpin, sehingga mereka bersedia secara sukarela untuk mencapai target, tujuan dan visi organisasi. (Robbins, 2001) mengkonfirmasi bahwa pemimpin transformasional adalah mereka yang mampu menginspirasi pengikut mereka untuk mengubah hidup mereka dan bercita-cita untuk tujuan dan visi yang lebih besar. Dalam definisi (Luthans, 2005), pemimpin transformatif mampu mengubah kesadaran pengikut mereka, meningkatkan semangat mereka, dan memotivasi mereka untuk melakukan yang terbaik untuk mencapai tujuan organisasi, bukan karena mereka dipaksa untuk, tetapi mereka bersedia. Menurut (Bass \& Avolio, 2000), ada tiga karakteristik pemimpin transformatif, yaitu: pertama, untuk meningkatkan kesadaran pengikut tentang pentingnya proses dan upaya. Kedua, untuk memotivasi pengikut untuk memprioritaskan kepentingan kelompok lebih dari kepentingan individu. Ketiga, untuk mengalihkan kebutuhan pengikut di luar hal-hal materi ke tingkat yang lebih tinggi seperti harga diri dan aktualisasi.

Dengan kata lain, (Burn, 1978) menyatakan bahwa pemimpin transformatif adalah orang-orang yang mendorong pengikut untuk bertindak untuk tujuan tertentu yang mewakili nilai-nilai dan motivasi-keinginan dan kebutuhan, aspirasi dan harapan dari para pemimpin dan pengikut. Mereka mampu mengubah kesadaran pengikut dan menanamkan nilainilai normatif, cita-cita, untuk mencapai moralitas yang lebih 
tinggi, seperti kesetaraan, kebebasan, keadilan, humanitarianisme, dan kedamaian.

\section{Kesiapan untuk Berubah}

Penelitian yang dilakukan oleh (Holt et al., 2007) menunjukkan bahwa kesiapan untuk perubahan adalah multidimensi yang dipengaruhi oleh keyakinan karyawan bahwa (a) mereka mampu mengimplementasikan perubahan yang diusulkan (yaitu, change efficacy), (b) perubahan yang diusulkan sesuai untuk organisasi (yaitu, appropriateness), (c) para pemimpin berkomitmen untuk perubahan yang diusulkan (yaitu, management support), dan (d) perubahan yang diusulkan bermanfaat bagi organisasi anggota (yaitu, personal benefit). Masih menurut (Holt et al., 2007), indikator yang dapat digunakan untuk mengukur tinggi rendahnya kesiapan untuk berubah karyawan antara lain: (1) keyakinan karyawan bahwa perubahan yang diusulkan akan tepat bagi organisasi, (2) keyakinan karyawan bahwa organisasi akan mendapatkan keuntungan dari penerapan perubahan, (3) karyawan akan meyakini adanya alasan yang logis untuk berubah dan adanya kebutuhan untuk perubahan yang diusulkan, (4) karyawan berfokus pada manfaat dari perubahan bagi perusahaan, (5) keyakinan karyawan tentang kemampuannya untuk menerapkan perubahan yang diinginkan, (6) karyawan merasa bahwa pemimpin dan manajemen dalam organisasi memiliki komitmen dan mendukung pelaksanaan perubahan yang diusulkan, (7) karyawan merasa bahwa ia akan memperoleh manfaat dari pelaksanaan perubahan yang diusulkan.

Untuk mempersiapkan karyawan agar siap berubah pada organisasi maka diperlukan pemahaman mengenai cara-cara yang dapat digunakan dalam menumbuhkan kesiapan untuk berubah. Terdapat dua hal yang dapat dilakukan oleh organisasi yaitu membentuk kesiapan karyawan untuk berubah dan menyelesaikan masalah penolakan untuk berubah (Banjongprasert, 2017). (Hadiyani, 2014; Pramadani, 2012) mengungkapkan bahwa komitmen organisasi dapat mempengaruhi kesiapan untuk berubah. Komitmen organisasi merupakan keinginan untuk tetap menjadi anggota organisasi, kepercayaan dan penerimaan nilai-nilai dan tujuan organisasi serta kesediaan untuk berusaha sebaik mungkin demi kepentingan organisasi. Selain itu employee engagement (keterlibatan kerja) memiliki peranan dalam keberhasilan implementasi perubahan organisasi, terutama yang berskala besar yang melibatkan seluruh elemen dari organisasi. Karyawan yang terlibat dalam kegiatan organisasi akan cenderung mendukung jalannya perubahan organisasi dan siap untuk berubah.

\section{Kinerja Karyawan}

Kinerja adalah perilaku bagaimana target berhasil dicapai (Armstrong \& Taylor, 2014). Kinerja merupakan proses berorientasi tujuan yang diarahkan untuk memastikan bahwa proses-proses keorganisasian ada pada tempatnya untuk memaksimalkan produktivitas para karyawan, tim, dan akhirnya, organisasi. Pendapat lain, kinerja merupakan apa yang dilakukan 
atau tidak dilakukan oleh karyawan (Luthans, 2005). Untuk dapat mengetahui kinerja karyawan pada suatu organisasi maka diperlukan beberapa aspek tertentu. Kinerja dipengaruhi oleh variabel yang terkait dengan pekerjaan meliputi role-stress dan konflik kerja/nonkerja (Babin \& Boles, 1998). Terdapat beberapa kriteria dalam mengukur kinerja, yakni: Kualitas, kuantitas, ketepatan waktu, efektivitas biaya dan hubungan antar personal (Bernardin \& Russel, 1993). Sedangkan (Mathis \& Jackson, 2002) menyebutkan bahwa kinerja karyawan memiliki beberapa elemen, yaitu: kuantitas, kualitas, ketepatan, kehadiran, kemampuan kerjasama, dan kesetiaan.

\section{Hubungan antara}

\section{Kepemimpinan}

Transformasional dan Kinerja

\section{Karyawan}

Studi dari (Asbari,

Purwanto, et al., 2019; Asbari, Purwanto, \& Budi, 2020; Purwanto, Asbari, et al., 2019; Purwanto, Mayesti Wijayanti, et al., 2019) menunjukkan bahwa kepemimpinan transformasional berhubungan positif dengan kinerja organisasi, dengan mediasi atau tanpa variabel mediasi. Penelitian lain juga menemukan temuan serupa, seperti studi dari (Bernarto et al., 2020; Purwanto, Wijayanti, et al., 2019; Purwanto, Asbari, Prameswari, et al., 2020c, 2020d). Berdasarkan hasil dan kesimpulan penelitian-penelitian sebelummnya, maka peneliti membuat hipotesis sebagai berikut:
$H^{1}$ : Kepemimpinan transformasional memiliki pengaruh terhadap kinerja karyawan.

\section{Hubungan antara Kepemimpinan \\ Transformasional dan Kesiapan untuk Berubah}

Penelitian terdahulu menyimpulkan bahwa kepemimpinan transformasional tidak berpengaruh signifikan terhadap kesiapan untuk berubah (Susyanto, 2019). Berbeda dengan kesimpulan penelitian (Mahessa \& NRH, 2016) yang menemukan bukti bahwa kepemimpinan memberikan pengaruh positif dan signifikan terhadap kesiapan untuk berubah pada karyawan BPJS Ketenagakerjaan. Demikian juga kesimpulan dari penelitian (Mujiburrahman et al., 2017), (Fitriana \& Sugiyono, 2019), dan (Astuti \& Khoirunnisa, 2018). Berdasarkan hasil kesimpulan penelitian terdahulu, maka penulis menyusun hipotesis kedua sebagai berikut:

$H^{2}$ : Kepemimpinan transformasional memiliki pengaruh terhadap kesiapan untuk berubah karyawan.

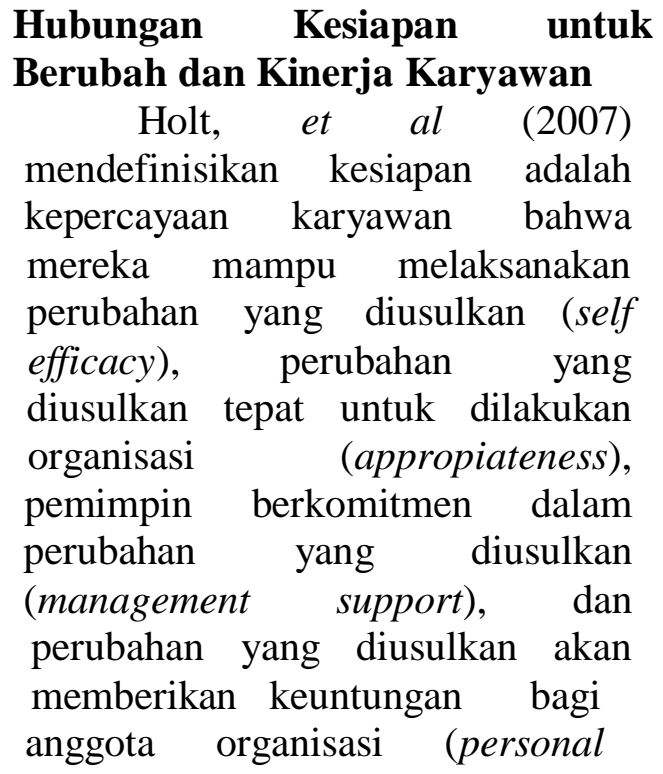


benefit). Dari penjelasan Holt, et al (2007) seorang karyawan yang dinyatakan siap untuk berubah akan menunjukkan perilaku menerima, merangkul, dan mengadopsi rencana perubahan yang dilakukan. Sebelum karyawan berada pada posisi siap, karyawan merefleksikan content, context, process, dan atribut individu untuk mempersepsikan dan mempercayai perubahan yang akan dilakukan organisasi. Kesiapan untuk berubah menjadi faktor penting dalam menciptakan kesuksesan perubahan (Armenakis, et al 1993). Hal ini dapat ditunjukkan bahwa ketika perubahan dilakukan akan muncul dua sikap yaitu positif dan negatif. Sikap positif ditunjukkan dengan adanya kesiapan untuk berubah dan sikap negatif ditunjukkan dengan adanya penolakan terhadap perubahan. Menciptakan sikap positif dalam diri karyawan dapat dilakukan dengan menciptakan kesiapan untuk berubah pada diri karyawan sehingga perubahan yang dilakukan dapat mencapai kesuksesan yang diharapkan.

$H^{3}$ : Kesiapan untuk berubah memiliki pengaruh terhadap kinerja karyawan.

\section{Pengaruh Kepemimpinan Transformasional terhadap Kinerja Karyawan melalui Kesiapan untuk Berubah Sebagai Mediator}

Beberapa
menyimpulkan bahwa variabel
kepemimpinan transformasional
memiliki hubungan yang signifikan
terhadap variabel kinerja karyawan
melalui kesiapan untuk berubah

(Katsaros et al., 2020). Secara parsial, beberapa penelitian lainnya menyebutkan terhadap pengaruh signifikan kepemimpinan transformasional terhadap kesiapan untuk berubah (Astuti \& Khoirunnisa, 2018; Sari, 2018), dan terdapat pengaruh signifikan kesiapan untuk berubah terhadap kinerja karyawan (Fitriana \& Sugiyono, 2019). Belum banyak penelitian yang memberikan model hubungan mediasi variable kesiapan untuk berubah terhadap hubungan antara variable kepemimpinan transformasional dan variable kinerja karyawan. Oleh karena itu, penulis berupaya untuk menyusun hipotesisi keempat ini sebagai berikut:

$\mathrm{H}^{4}$ : Kepemimpinan transformasional memiliki pengaruh terhadap kinerja karyawan melalui kesiapan untuk berubah sebagai mediator.

\section{Metodologi Penelitian}

\section{Definisi Operasional Variabel dan Indikator}

\begin{tabular}{lrrr}
\multicolumn{2}{c}{ Metode yang } & digunakan \\
dalam penelitian & ini & adalah \\
metode & kuantitatif. & Dilakukan \\
pengumpulan & data & dengan \\
mengedarkan & angket & kepada \\
seluruh karyawan industry & retail di \\
Jawa Barat. Instrumen & yang \\
digunakan untuk & mengukur \\
transformational & leadership \\
diadaptasi dari (Bogler, & 2001) \\
dengan menggunakan & 5 & items \\
(TL1-TL5). Kesiapan & untuk \\
berubah diadaptasi dari & (Holt et \\
al., 2007) dengan menggunakan 7 \\
items (RTC1-RTC7). & Kinerja \\
karyawan & diadaptasi & dari
\end{tabular}
(Bernardin \& Russel, 1993) dengan menggunakan 6 items (WP1-WP6). 
Model penelitian bias dilihat sebagaimana pada Gambar 1. Angket didesain tertutup kecuali untuk pertanyaan/pernyataan mengenai identitas responden yang berupa angket semi terbuka. Tiap item pertanyaan/pernyataan tertutup diberikan lima opsi jawaban, yaitu: sangat setuju (SS) skor 5, setuju (S) skor 4, netral/ ragu-ragu $(\mathrm{N})$ skor 3, tidak setuju (TS) skor 2, dan sangat tidak setuju (STS) skor 1. Metode untuk mengolah data adalah dengan PLS dan menggunakan software SmartPLS versi 3.0 sebagai toolnya.

\section{Populasi dan Sampel}

Populasi dalam penelitian ini adalah karyawan dari salah satu industri retail di Jawa Barat yang jumlahnya 315 orang. Kuesioner disebarkan dengan teknik simple random sampling. Hasil kuesioner yang kembali sebanyak valid adalah 214 sampel. Jadi jumlah sampel adalah $67.94 \%$ dari jumlah populasi.

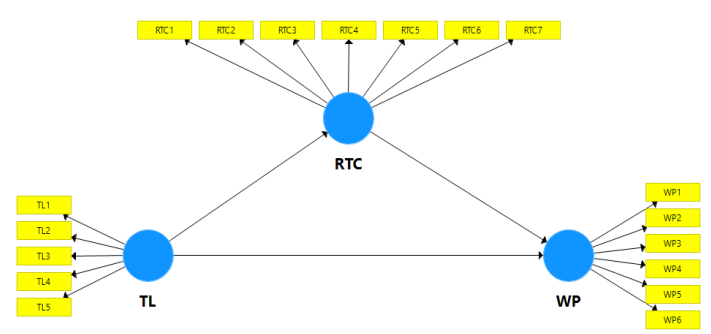

Gambar 1. Model Penelitian

Hasil

\section{Deskripsi Sampel}

Table 1. Sample Descriptive Information

\begin{tabular}{|c|c|c|c|}
\hline \multicolumn{2}{|c|}{ Kriteria } & \multirow{2}{*}{$\begin{array}{c}\text { Jumlah } \\
57\end{array}$} & \multirow{2}{*}{$\frac{\%}{26.6 \%}$} \\
\hline Usia & $\begin{array}{l}<30 \\
\text { tahun }\end{array}$ & & \\
\hline & $\begin{array}{l}30- \\
40 \\
\text { tahun }\end{array}$ & 104 & $48.6 \%$ \\
\hline & $\begin{array}{l}>40 \\
\text { tahun }\end{array}$ & 53 & $24.8 \%$ \\
\hline $\begin{array}{l}\text { Masa kerja } \\
\text { sebagai }\end{array}$ & $\begin{array}{l}<5 \\
\text { tahun }\end{array}$ & 80 & $37.4 \%$ \\
\hline \multirow[t]{2}{*}{ karyawan } & $\begin{array}{l}5-10 \\
\text { tahun }\end{array}$ & 109 & $50.9 \%$ \\
\hline & $\begin{array}{l}>10 \\
\text { tahun }\end{array}$ & 25 & $11.7 \%$ \\
\hline \multirow{2}{*}{$\begin{array}{l}\text { Ijazah } \\
\text { tertinggi }\end{array}$} & $\mathrm{S} 1$ & 13 & $6.1 \%$ \\
\hline & $\begin{array}{l}\geq \\
\text { SMA }\end{array}$ & 201 & $93.9 \%$ \\
\hline
\end{tabular}

Responden penelitian mayoritas telah berusia dewasa di atas 30 tahun, yakni sebanyak $73.4 \%$. Masa kerja mayoritas di atas 5 tahun, yakni sebanyak 62.6\%. Pendidikan responden mayoritas di bawah sarjana, jadi pendidikan responden di Antara tingkat SMA hingga diploma 3 (D3), yakni sebanyak $93.9 \%$.

\section{Hasil Uji Validitas dan Reliabilitas Indikator Penelitian}

Tahap pengujian model pengukuran meliputi pengujian validitas konvergen, validitas diskriminan. Sementara untuk menguji reliabilitas konstruk digunakan nilai cronbach's alpha dan composite reliability. Hasil analisis PLS dapat digunakan untuk menguji hipotesis penelitian jika seluruh indikator dalam model PLS telah memenuhi syarat 
validitas konvergen, validitas deskriminan dan uji reliabilitas.

\section{Pengujian Validitas Konvergen}

Uji validitas konvergen dilakukan dengan melihat nilai loading factor masing-masing indikator terhadap konstruknya. Pada sebagian besar referensi, bobot faktor sebesar 0.5 atau lebih dianggap memiliki validasi yang cukup kuat untuk menjelaskan konstruk laten (Chin, 1998; Ghozali, 2014; Hair et al., 2010). Pada penelitian ini batas minimal besarnya loading factor yang diterima adalah 0.5 , dengan syarat nilai AVE setiap konstruk > 0.5 (Ghozali, 2014). Setelah melalui pengolahan SmartPLS 3.0, ada beberapa indikator atau item yang perlu dikeluarkan dari model, yakni: WP4 dan WP6. Selanjutnya, setelah itu, seluruh indikator telah memiliki nilai loading factor di atas 0.5 atau dengan syarat nilai AVE di atas 0.5. Model fit atau valid dari penelitian ini bias dilihat pada Gambar 2. Jadi dengan demikian, validitas konvergen dari model penelitian ini sudah memenuhi syarat. Nilai loadings, cronbach's alpha, composite reliability dan AVE setiap konstruk selengkapnya dapat dilihat Tabel 2 berikut:

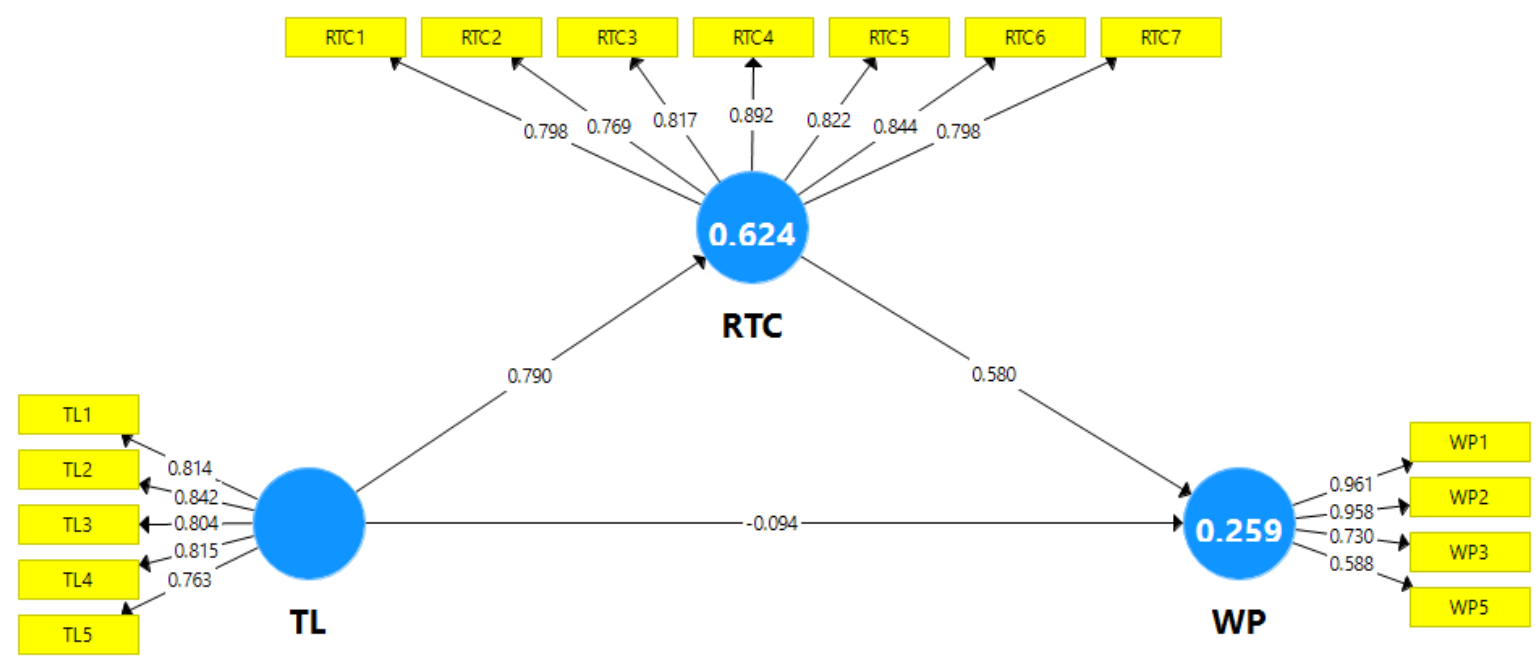

Gambar 2. Model Penelitian Valid

Tabel 2. Items Loadings, Cronbach's Alpha, Composite Reliability, and Average Variance Extracted (AVE)

\begin{tabular}{llllll}
\hline Varables & Items & Loadings & $\begin{array}{c}\text { Cronbach's } \\
\text { Alpha }\end{array}$ & $\begin{array}{c}\text { Composite } \\
\text { Reliability }\end{array}$ & AVE \\
\hline Kepemimpinan & TL1 & 0.814 & 0.867 & 0.904 & 0.653 \\
Transformasional (TL) & TL2 & 0.842 & & & \\
& TL3 & 0.804 & & & \\
& TL4 & 0.815 & & & \\
& TL5 & 0.763 & & 0.935 & 0.673
\end{tabular}




\begin{tabular}{llllll} 
(RTC) & RTC2 & 0.769 & & & \\
& RTC3 & 0.817 & & \\
& RTC4 & 0.892 & & \\
& RTC5 & 0.822 & & & \\
& RTC6 & 0.844 & & & \\
& RTC7 & 0.798 & & 0.680 \\
& WP1 & 0.961 & 0.846 & & \\
\hline Kinerja Karyawan & WP2 & 0.958 & & & \\
(WP) & WP3 & 0.730 & & & \\
& WP5 & 0.588 & & & \\
& & & & & \\
\hline
\end{tabular}

Tabel 3. Discriminant Validity

\begin{tabular}{llll}
\multicolumn{1}{c}{ Variables } & RTC & TL & WP \\
\hline Kesiapan untuk Berubah (RTC) & $\mathbf{0 . 8 2 1}$ & & \\
Kepemimpinan Transformasional (TL) & 0.790 & $\mathbf{0 . 8 0 8}$ & \\
Kinerja Karyawan (WP) & 0.506 & 0.365 & $\mathbf{0 . 8 2 4}$ \\
\hline
\end{tabular}

Tabel 4. Collinearity Statistics (VIF)

\begin{tabular}{lll}
\hline \multicolumn{1}{c}{ Variables } & $\begin{array}{c}\text { Kesiapan untuk } \\
\text { Berubah (RTC) }\end{array}$ & $\begin{array}{c}\text { Kinerja Karyawan } \\
\text { (WP) }\end{array}$ \\
\hline Kesiapan untuk Berubah (RTC) & & 2.663 \\
Kepemimpinan Transformasional (TL) & 1.000 & 2.663 \\
\hline
\end{tabular}

\section{Pengujian Validitas Deskriminan}

\section{Discriminant validity}

dilakukan untuk memastikan bahwa setiap konsep dari masing-masing variabel laten berbeda dengan variabel laten lainnya. Model mempunyai discriminant validity yang baik jika nilai kuadrat AVE masing-masing konstruk eksogen (nilai pada diagonal) melebihi korelasi antara konstruk tersebut dengan konstruk lainnya (nilai di bawah diagonal) (Ghozali, 2014) . Hasil pengujian discriminant validity adalah dengan menggunakan nilai kuadrat AVE, yakni dengan melihat FornellLarcker Criterion Value diperoleh sebagaimana ditunjukkan pada Tabel 3. Hasil uji validitas deskriminan pada tabel 3 di atas menunjukkan bahwa seluruh konstruk telah memiliki nilai akar kuadrat AVE di atas nilai korelasi dengan konstruk laten lainnya (melalui kriteria Fornell-Larcker). Demikian juga nilai cross-loading seluruh item dari suatu indikator lebih besar dari item indikator lainnya sebagaimana disebut pada Tabel 4, sehingga dapat disimpulkan bahwa model telah memenuhi validitas deskriminan (Fornell \& Larcker, 1981). Selanjutnya, evaluasi kolinearitas dilakukan untuk mengetahui apakah ada kolinearitas dalam model. Untuk menemukan collinearity, diperlukan penghitungan VIF dari setiap konstruk. Jika skor VIF lebih tinggi dari 5, maka model tersebut memiliki collinearity (Hair 
et al., 2014). Sebagaimana ditunjukkan pada Tabel 4, semua skor VIF lebih kecil dari 5, artinya bahwa model ini tidak memiliki masalah collinearity.

\section{Pengujian Reliabilitas Konstruk}

Reliabilitas konstruk dapat dinilai dari nilai cronbach's alpha dan composite reliability dari masing-masing konstruk. Nilai composite reliability dan cronbach's alpha yang disarankan adalah lebih dari 0.7 (Ghozali, 2014). Hasil uji reliabilitas pada tabel 2 di atas menunjukkan bahwa seluruh konstruk telah memiliki nilai composite reliability dan cronbach's alpha lebih besar dari 0.7 (> 0.7). Kesimpulannya, seluruh konstruk telah memenuhi reliabilitas yang dipersyaratkan.
Pengujian Hipotesis

Pengujian hipotesis dalam PLS disebut juga sebagai uji inner model. Uji ini meliputi uji signifikansi pengaruh langsung dan tidak langsung serta pengukuran besarnya pengaruh variabel eksogen terhadap variabel endogen. Untuk mengetahui pengaruh kepemimpinan transformasional terhadap kinerja karyawan dengan melalui kesiapan untuk berubah sebagai variable mediasi dibutuhkan uji pengaruh langsung dan tidak langsung. Uji pengaruh dilakukan dengan menggunakan uji t-statistik dalam model analisis partial least squared (PLS) dengan menggunakan bantuan software SmartPLS 3.0. Dengan teknik boothstrapping, diperoleh nilai $R$ Square dan nilai uji signifikansi sebagaimana Tabel 5 dan Tabel 6 di bawah ini:

Tabel 5. Nilai $R$ Square

\begin{tabular}{lcc}
\hline & R Square & \multicolumn{1}{c}{ R Square Adjusted } \\
\hline Kesiapan untuk Berubah (RTC) & 0.624 & 0.623 \\
Kinerja Karyawan (WP) & 0.259 & 0.253 \\
\hline
\end{tabular}

Tabel 6. Hypotheses Testing

\begin{tabular}{llccccc}
\hline Hypotheses & Relationship & Beta & SE & T Statistics & P-Values & Decision \\
\hline H1 & TL $>$ WP & -0.094 & 0.101 & 0.930 & 0.353 & $\begin{array}{c}\text { Not } \\
\text { Supported }\end{array}$ \\
H2 & TL $>$ RTC & 0.790 & 0.032 & 24.999 & 0.000 & Supported \\
H3 & RTC $>$ WP & 0.580 & 0.088 & 6.566 & 0.000 & Supported \\
H4 & TL $>$ RTC $\rightarrow$ & 0.458 & 0.078 & 5.894 & 0.000 & Supported \\
& WP & & & & & \\
\hline
\end{tabular}

Berdasarkan Tabel 5 di atas, nilai $R$ Square kesiapan untuk berubah (RTC) sebesar 0.624 yang berarti bahwa variable kesiapan untuk berubah (RTC) mampu dijelaskan oleh variabel kepemimpinan 
transformasional (TL) sebesar $62.4 \%$, sedangkan sisanya sebesar $37.6 \%$ dijelaskan oleh variabel lain yang tidak dibahas dalam penelitian ini. Nilai $R$ Square kinerja karyawan (WP) sebesar 0.259 yang berarti bahwa variabel kinerja karyawan (WP) mampu dijelaskan oleh variabel kepemimpinan transformasional (TL) dan kesiapan untuk berubah (RTC) sebesar 25.9\%, sedangkan sisanya sebesar $74.1 \%$ dijelaskan oleh variabel lain yang tidak dibahas dalam penelitian ini. Sedangkan Tabel 6 menampilkan $t$ statistics dan p-values yang menunjukkan pengaruh antar variable penelitian yang telah disebutkan.

\section{Pembahasan}

\section{Pengaruh Kepemimpinan Transformasional terhadap Kinerja Karyawan}

Berdasarkan penghitungan statistic yang diringkas pada Tabel 6 di atas, disimpulkan bahwa kepemimpinan transformasional tidak secara signifikan mempengaruhi kinerja karyawan di industri. Terbukti dengan nilai t-statistics 0.930 lebih kecil dari 1.96 dan nilai p-values sebesar 0.353 lebih besar dari 0.05 . Artinya, hipotesis pertama (H1) ditolak atau tidak diterima. Temuan ini bertentangan dengan hasil penelitian sebelumnya dari (Asbari, 2019; Asbari, Santoso, et al., 2019; Asbari, Purwanto, et al., 2019; Asbari, Purwanto, \& Budi, 2020; Asbari, Fayzhall, et al., 2020; Fayzhall, Asbari, Purwanto, Basuki, et al., 2020; Fayzhall, Asbari, Purwanto, Goestjahjanti, et al., 2020; Purwanto, Asbari, et al., 2019;
Purwanto, Mayesti Wijayanti, et al., 2019; Purwanto, Wijayanti, et al., 2019; Purwanto, Asbari, Prameswari, et al., 2020c, 2020d; Purwanto, Asbari, \& Hadi, 2020b, 2020a; Purwanto, Pramono, Asbari, et al., 2020g; Purwanto, Bernarto, Asbari, et al., 2020e; Purwanto, Asbari, Budi Santoso, et al., 2020a). Seperti disebutkan sebelumnya, proses transformasi di industri sebagai indikator utama untuk variabel kepemimpinan transformasional hanya berlangsung untuk waktu yang cukup singkat. Transformasi dimulai dengan perubahan struktur organisasi, pengangkatan pemimpin baru, dan kemudian perubahan sistem kerja dan budaya. Responden penelitian ini merasa bahwa kinerja karyawan di industri tidak dipengaruhi oleh perubahan di atas, karena prosesnya berlangsung untuk waktu yang cukup singkat. Walaupun demikian, penelitian ini sejalan dengan kesimpulan dari penelitian (Fayzhall, Asbari, Purwanto, Basuki, et al., 2020; Fayzhall, Asbari, Purwanto, Goestjahjanti, et al., 2020; Hutagalung et al., 2020; Purwanto, Mayesti Wijayanti, et al., 2019; Purwanto, Wijayanti, et al., 2019; Purwanto, Asbari, \& Hadi, 2020a, 2020b; Purwanto, Asbari, Prameswari, et al., 2020c) yang menemukan bukti bahwa kepemimpinan tidak berpengaruh signifikan terhadap kinerja. Temuan ini telah memberikan umpan balik yang bermanfaat bagi manajemen industri yang mencoba untuk memulai perubahan, di mana proses tersebut membutuhkan upaya sosialisasi dan diseminasi yang konstan, sehingga setiap anggota organisasi memahami sepenuhnya 
kebutuhan akan perubahan tersebut, dan pada gilirannya akan mendukung proses. Temuan yang berbeda juga disebabkan oleh konteks yang berbeda antara organisasi publik dan swasta, juga berbeda antara organisasi jasa dan industri.

\section{Pengaruh}

Kepemimpinan Transformasional terhadap Kesiapan untuk Berubah

Berdasarkan penghitungan statistic yang diringkas pada Tabel 6 di atas, disimpulkan bahwa kepemimpinan transformasional secara positif dan signifikan mempengaruhi kesiapan untuk berubah pada karyawan di industri. Terbukti dengan nilai $t$-statistics 24.999 lebih besar dari 1.96 dan nilai $p$-values sebesar 0.000 lebih kecil dari 0.05 . Artinya, hipotesis kedua (H2) diterima. Temuan ini sesuai dengan kesimpulan temuan empiris dan teoritis dari penelitian sebelumnya dari (Astuti \& Khoirunnisa, 2018; Fitriana \& Sugiyono, 2019; Mahessa \& NRH, 2016) yang mengkonfirmasi bahwa kepemimpinan transformasional secara signifikan mempengaruhi kesiapan untuk berubah pada karyawan.

\section{Pengaruh Kesiapan untuk Berubah terhadap Kinerja Karyawan}

Berdasarkan penghitungan statistic yang diringkas pada Tabel 6 di atas, disimpulkan bahwa kesiapan untuk berubah secara positif dan signifikan mempengaruhi kinerja karyawan di industri. Terbukti dengan nilai t-statistics 6.566 lebih besar dari 1.96 dan nilai p-values sebesar
0.000 lebih kecil dari 0.05. Artinya, hipotesis ketiga (H3) diterima. Kesimpulan penelitian ini mendukung apa yang telah ditemukan pada penelitian sebelumnya, bahwa kesiapan untuk berubah berpengaruh positif dan signifikan terhadap kinerja (Banjongprasert, 2017; Katsaros et al., 2020).

\section{Pengaruh Kepemimpinan}

Transformasional terhadap Kinerja Karyawan melalui Kesiapan untuk Berubah sebagai Mediator

Berdasarkan penghitungan statistic yang diringkas pada Tabel 6 di atas, disimpulkan bahwa kesiapan untuk berubah secara positif dan signifikan mempengaruhi kinerja karyawan melalui kesiapan untuk berubah pada karyawan di industri. Terbukti dengan nilai $t$-statistics 5.894 lebih besar dari 1.96 dan nilai $p$-values sebesar 0.000 lebih kecil dari 0.05. Artinya, hipotesis ketiga (H4) diterima. Kesimpulan penelitian ini mendukung apa yang telah ditemukan pada penelitian sebelumnya oleh (Katsaros et al., 2020) yang menyimpulkan bahwa kesiapan untuk berubah mampu memediasi hubungan pengaruh kepemimpinan terhadap kinerja karyawan.

\section{Simpulan}

ini, $\begin{array}{cr}\text { Berdasarkan hasil penelitian } \\ \text { disimpulkan }\end{array}$ kepemimpinan transformasional tidak memberikan pengaruh yang signifikan terhadap tinggirendahnya tingkat kinerja karyawan di industry retail. Tetapi, ternyata keyakinan dan semangat kesiapan untuk berubah pada diri karyawan 
mampu mempertahankan tetap baiknya kinerja. Ada hal menarik yang bias diperhatikan dari hasil penelitian ini, bahwa di era pandemic Covid-19 ini, praktek kepemimpinan transformasional tidak berpengaruh signifikan terhadap kinerja karyawan, tetapi berpengaruh positif dan signifikan terhadap kesiapan untuk berubah. Mengapa demikian? Jawabannya bisa jadi karena usia karyawan mayoritas sudah dewasa, yakni di atas 40 tahun $(74.59 \%)$ dan masa kerja karyawan dominan lebih dari 5 tahun (64.34\%), artinya keberadaan praktek kepemimpinan transformasional sudah tidak banyak memberikan pengaruh terhadap kinerja karyawan, karena mereka sudah relative lebih mandiri. Di sisi lain, kepemimpinan transformasional mampu memberikan pengaruh yang positif dan signifikan terhadap kesiapan untuk berubah pada diri karyawan di masa pandemic covid19 ini, mengapa demikian? Jawabannya, di dalam praktek kepemimpinan, terdapat dimensi keteladan dan mempengaruhi yang sangat dominan. Briefing dan sesi rapat yang kerap diadakan oleh pemimpin mampu memunculkan kesadaran dan keyakinan kuat kepada karyawan bahwa pandemic covid-19 ini akan bisa berakhir dan normal kembali. Di samping itu, motivasi yang diberikan oleh pemimpin transformasional memberikan keyakinan bahwa pasca pandemic, perusahaan akan memiliki kinerja lebih lagi karena mampu melihat peluang-peluang baru di masa depan. Di samping itu, penelitian ini menemukan bukti bahwa kesiapan untuk berubah mampu menjadi mediasi penuh terhadap hubungan antara kepemimpinan transformasional dan kinerja karyawan.

\section{Managerial Implications}

Berdasarkan hasil temuan penelitian ini, disarankan kepada manajemen industry retail untuk memperhatikan praktek kepemimpinan transformasional yang lebih baik sehingga tetap mampu memberikan dampak positif terhadap kinerja karyawan, atau jika tidak mungkin mempertahankan praktek kepemimpinan transformasional lagi, manajemen perlu mempertimbangkan praktek gaya kepemimpinan baru yang lebih sesuai dengan kondisi karyawan industry retail saat ini yang mayoritas sudah dewasa (74.59\%) dan masa kerja sudah cukup lama, yang sudah di atas 5 tahun sebanyak $64.34 \%$. Berikutnya, manajemen perlu mempertahankan kebiasaan memberikan briefing dan motivasi para pemimpin di perusahaan untuk terus menjaga kesiapan untuk berubah pada diri karyawan, lebih-lebih di masa pandemic Covid-19 ini. Karena kesiapan untuk berubah adalah modal dasar dari kesiapan karyawan untuk menghadapi kompetisi di era revolusi industry 4.0.

\section{Limitasi}

Penelitian ini memiliki beberapa keterbatasan. Pertama, penelitian ini menganalisis pengaruh kepemimpinan transformasional terhadap kinerja karyawan baik secara langsung maupun tidak langsung melalui variabel kesiapan untuk berubah. Karena mungkin ada beberapa variabel lain (seperti motivasi, kompetensi, manajemen 
pengetahuan, budaya organisasi, dll) yang mempengaruhi kinerja karyawan. Penulis sangat merekomendasikan untuk menemukan, mengeksplorasi, dan menganalisisnya pada penelitianpenelitian berikutnya. Kedua, penelitian ini dilakukan di industri pabrikan dan mungkin tidak bisa digeneralisasi ke industri lain. Oleh karena itu, sangat disarankan untuk melakukan penelitian lebih lanjut tentang topik ini di industri lain. Mungkin dapat ditambahkan ke seluruh wilayah, atau di negara lain, atau diperbandingan antara UKM dan organisasi besar.

\section{Daftar Pustaka}

Agistiawati, E., Asbari, M., Basuki, S., Yuwono, T., \& Chidir, G. (2020). Exploring the Impact of Knowledge Sharing and Organizational Culture on Teacher Innovation Capability. International Journal of Science and Management Studies (IJSMS), 3(3), 62-77.

http://www.ijsmsjournal.org/current -issue.html

Armstrong, M., \& Taylor, S. (2014). Human Resource Management Practice. Ashford Colour Press Ltd.

Asbari, M. (2015). Fokus Satu Hebat. Penerbit Dapur Buku.

Asbari, M. (2019). Pengaruh kepemimpinan transformasional dan iklim organisasi terhadap kinerja dosen. JOCE IP, 13(2), 172-186. http://jurnal.ipem.ac.id/index.php/jo ce-ip/article/view/187

Asbari, M., Chi Hyun, C., Wijayanti, L. M., Imelda, D., \& Purwanto, A. (2020). Hard Skills Atau Soft Skills: Manakah Yang Lebih Penting Bagi Inovasi Guru. Edumaspul - Jurnal Pendidikan, 4(1), 1-20. https://www.researchgate.net/public ation/339274657_HARD_SKILLS_ ATAU_SOFT_SKILLS_MANAK AH_YANG_LEBIH_PENTING_B AGI_INOVASI_GURU

Asbari, M., Fayzhall, M., Goestjahjanti, F. S., Winanti, Yuwono, T., Hutagalung, D., Basuki, S., Maesaroh, S., Mustofa, Chidir, G., Yani, A., \& Purwanto, A. (2020). Peran Kepemimpinan Transformasional Dan Organisasi Pembelajaran Terhadap Kapasitas Inovasi Sekolah. EduPsyCouns: Journal of Education, Psychology and Counseling, 2(1), 6724-6748. https://ummaspul.ejournal.id/Edupsycouns/article/view /421

Asbari, M., Hyun, C. C., Wijayanti, L. M., WINANTI, W., Fayzhall, M., \& Putra, F. (2020). Hard Skills Dan Soft Skills: Apa Membangun Inovasi Guru Sekolah Islam? Journal EVALUASI, 4(1), 143. https://doi.org/10.32478/evaluasi.v4 i1.362

Asbari, M., Pramono, R., Kotamena, F., Juliana, Sihite, O. B., Alamsyah, V. U., Imelda, D., Setiawan, S. T., \& Purwanto, A. (2020). Bekerja Sambil Kuliah dalam Perspektif Self-Management (Studi Etnografi pada Karyawan Etnis Jawa di Kota Seribu Industri Jawa Barat). Edumaspul - Jurnal Pendidikan, 4(1), 1-10. https://doi.org/https://doi.org/10.33 487/edumaspul.v4i1.363

Asbari, M., Purwanto, A., \& Budi, P. (2020). Pengaruh Iklim Organisasi dan Kepemimpinan Transformasional Terhadap Produktivitas Kerja Inovatif Pada Industri Manufaktur di Pati Jawa Tengah . Jurnal Produktivitas, 7(1), 62-69.

https://doi.org/http://dx.doi.org/10.2 9406/jpr.v7i1.1797

Asbari, M., Purwanto, A., Fayzhall, M., 
Winanti, Purnamasari, D., \& Firdaus, R. A. (2020). Hard skills or soft skills: Which are more important for Indonesian teachers innovation. Test Engineering and Management, 83(2836), 2836-2854. http://www.testmagzine.biz/index.p $\mathrm{hp} /$ testmagzine/article/view/4087

Asbari, M., Purwanto, A., Maesaroh, S., Hutagalung, D., Mustikasiwi, A., Ong, F., \& Andriyani, Y. (2020). Impact of Hard Skills, Soft Skills and Organizational Culture : Lecturer Innovation Competencies As Mediating. EduPsyCouns: Journal of Education, Psychology and Counseling, 2(1), 142-155. https://ummaspul.ejournal.id/Edupsycouns/article/view 1419

Asbari, M., Purwanto, A., \& Santoso, P. B. (2019). Influence of Leadership, Motivation, Competence, Commitment and Culture on ISO 9001:2015 Performance in Packaging Industry. Scholars Journal of Economics, Business and Management, 6(12), 577-582. https://doi.org/10.36347/sjebm.201 9.v06i12.005

Asbari, M., Santoso, P. B., \& Purwanto, A. (2019). Pengaruh Kepemimpinan dan Budaya Organisasi Terhadap Perilaku Kerja Inovatif pada Industri 4.0. Jim Upb, 8(1), 7-15. https://doi.org/ttps://doi.org/10.338 84/jimupb.v8i1.1562

Asbari, M., Wijayanti, L., Hyun, C. C., Purwanto, A., \& Santoso, P. B. (2020). How to build innovation capability in the RAC industry to face industrial revolution 4.0? International Journal of Psychosocial Rehabilitation, 24(6), 2008-2027.

https://doi.org/10.37200/IJPR/V24I 6/PR260192

Asbari, M., Wijayanti, L. M., Hyun, C. C., Purwanto, A., Santoso, B., \& Article, H. (2019). Effect of Tacit and Explicit Knowledge Sharing on Teacher Innovation Capability. Dinamika Pendidikan, 14(2), 227243. https://doi.org/10.15294/dp.v14i2.2 2732

Astuti, E., \& Khoirunnisa, R. M. (2018). Pengaruh Employee Engagement, Komitmen Organisasi, Dan Kepemimpinan Transformasional Terhadap Kesiapan Untuk Berubah (Readiness For Change) Pada Karyawan Universitas Ahmad Dahlan. JURNAL FOKUS, 8(1), 4766.

Babin, B. J., \& Boles, J. S. (1998). Employee behavior in a service environment: A model and test of potential differences between men and women. Journal of Marketing, 62(2), 77-91. https://doi.org/10.2307/1252162

Banjongprasert, J. (2017). An Assessment of Change-Readiness Capabilities and Service Innovation Readiness and Innovation Performance : Empirical Evidence from MICE Venues. IJEM International Journal of Economics and Management, 11, $1-17$.

Bass, B., \& Avolio, B. (2000). Technical Report, Leader form, rater form, and Scoring Key of MLQ From 5x-Short. Mind Garden, Inc.

Bernardin, H., \& Russel, J. (1993). Human Resource Management: An Experimental Approach. Mc Graw Hill Companies.

Bernarto, I., Bachtiar, D., Sudibjo, N., Suryawan, I. N., Purwanto, A., \& Asbari, M. (2020). Effect of transformational leadership, perceived organizational support, job satisfaction toward life satisfaction: Evidences from indonesian teachers. International Journal of Advanced Science and Technology, 29(3), 5495-5503. http://sersc.org/journals/index.php/I JAST/article/view/6057 
Bogler, R. (2001). The influence of leadership style on teacher job satisfaction. Educational Administration Quarterly, 37(5), 662-683. https://doi.org/10.1177/0013161012 1969460

Burn, J. (1978). Leadership. Harper.

Chin, W. (1998). The Partial Least Squares Approach to Structural Equation Modeling (E. Modern Methods for Business Research, In: G. A. Marcoulides (ed.)). Lawrence Erlbaum Associates Publisher.

David, S., Armanu, \& Afnan, T. E. (2017). The Effects of Transformational Leadership and Personality on Employee Performance in Nissan Malang Mediated by Organizational Commitment. RJOAS, 3(19), 197210.

https://doi.org/https://doi.org/10.18 551/rjoas.2017-01.21

Eliyana, A., Ma'arif, S., \& Muzakki. (2019). Job satisfaction and organizational commitment effect in the transformational leadership towards employee performance. European Research on Management and Business Economics, 25(3), 144-150.

https://doi.org/10.1016/j.iedeen.201 9.05.001

Fayzhall, M., Asbari, M., Purwanto, A., Basuki, S., Hutagalung, D., Maesaroh, S., Chidir, G., Goestjahjanti, F. S., \& Andriyani, Y. (2020). Pengaruh Gaya Kepemimpinan Terhadap Kapabilitas Inovasi Guru Dalam Perspektif Organizational Learning. EduPsyCouns: Journal of Education, Psychology and Counseling, 2(1). https://ummaspul.ejournal.id/Edupsycouns/article/view 1413

Fayzhall, M., Asbari, M., Purwanto, A., Goestjahjanti, F. S., Yuwono, T., Radita, F. R., Yulia, Y., Cahyono,
Y., \& Suryani, P. (2020). Transformational versus Transactional Leadership: Manakah yang Mempengaruhi Kepuasan Kerja Guru? EduPsyCouns: Journal of Education, Psychology and Counseling, 2(1), 256-275. https://ummaspul.ejournal.id/Edupsycouns/article/view 1463

Fikri, M. A. A., Asbari, M., Purwanto, A., Nugroho, Y. A., Waruwu, H., Fauji, A., Shobihi, A. W., Singgih, E., Sudiyono, R. N., Agistiawati, E., \& Dewi, W. R. (2020). A Mediation Role of Organizational Learning on Relationship of Hard Skills, Soft Skills, Innovation and Performance: Evidence at Islamic School. EduPsyCouns: Journal of Education, Psychology and Counseling, 2(1), 398-423. https://ummaspul.ejournal.id/Edupsycouns/article/view 1498

Fitriana, R., \& Sugiyono. (2019). Kesiapan berubah pada sekretariat jenderal kementerian kelautan dan perikanan republik indonesia. IKRAITH EKONOMIKA VOL, 2(2), 42-51.

Fornell, C., \& Larcker, D. F. (1981). Evaluating Structural Equation Models with Unobservable Variables and Measurement Error. Journal of Marketing Research, 18(1), 39. https://doi.org/10.2307/3151312

Ghozali, I. (2014). Structural Equation Modeling, Metode Alternatif dengan Partial Least Square (PLS) (4th ed.). Badan Penerbit Universitas Diponegoro.

Hadiyani, S. (2014). Peranan Komitmen Organisasi dan Employee Engagement terhadap Kesiapan Karyawan untuk Berubah. JURNAL PSIKOLOGI, 41(1), 17-33.

Hair, J. F., Black, W. C., Babin, B. J., \& Anderson, R. E. (2010). 
Multivariate Data Analysis (7th ed.). Pearson Prentice Hall.

Hair, J. F., Hult, G. T., Ringle, C. M., \& Sarstedt, M. (2014). A primer partial least squaresstructural equation modeling (PLS-SEM). SAGE Publications.

Holt, D. T., Armenakis, A. A., Feild, H. S., \& Harris, S. G. (2007). The Journal of Applied Behavioral Science The Systematic Development of a Scale. Feild and Stanley G. Harris Journal of Ap, 43, 232. https://doi.org/10.1177/0021886306 295295

Hutagalung, D., Asbari, M., Fayzhall, M., Ariyanto, E., Agistiawati, E., Sudiyono, R. N., Waruwu, H., Goestjahjanti, F. S., Winanti, \& Yuwono, T. (2020). Peran Religiusitas, Kepemimpinan Transformasional, Kepuasan Kerja dan Mediasi Organizational Citizenship Behavior terhadap Kinerja Guru. EduPsyCouns: Journal of Education, Psychology and Counseling, 2(1), 311-326. https://ummaspul.ejournal.id/Edupsycouns/article/view 1483

Jumiran, Novitasari, D., Nugroho, Y. A., Sutardi, D., Sasono, I., \& Asbari, M. (2020). Pengaruh Dimensi Kepemimpinan Transformasional terhadap Kepuasan Kerja dan Komitmen Organisasional: Studi Kasus pada Dosen Perguruan Tinggi Swasta. EduPsyCouns: Journal of Education, Psychology and Counseling, 2(1), 600-621. https://ummaspul.ejournal.id/Edupsycouns/article/view 1555

Katsaros, K. K., Tsirikas, A. N., \& Kosta, G. C. (2020). The impact of leadership on firm financial performance: the mediating role of employees' readiness to change. Leadership \& Organization
Development Journal, 41(3), 333347.

https://doi.org/https://doi.org/10.11 08/LODJ-02-2019-0088

Khalifa Elgelal, K. S., \& Noermijati, N. (2014). The Influences of Transformational Leaderships on Employees Performance (A Study of the Economics and Business Faculty Employee at University of Muhammadiyah Malang). Asia Pacific Management and Business Application, 3(1), 48-66. https://doi.org/10.21776/ub.apmba. 2014.003.01.4

Luthans, F. (2005). Perilaku Organisasi (Edisi Kese). Penerbit ANDI.

Maesaroh, S., Asbari, M., Hutagalung, D., Agistiawati, E., Basuki, S., Radita, F. R., Nurasiah, Yulia, Y., Singgih, E., \& Chidir, G. (2020). Pengaruh Religiusitas dan Kepemimpinan Transformasional terhadap Kinerja Guru melalui Mediasi Organizational Citizenship Behavior. EduPsyCouns: Journal of Education, Psychology and Counseling, 2(1), 276-290. https://ummaspul.ejournal.id/Edupsycouns/article/view 1473

Mahessa, N. F., \& NRH, F. (2016). Gaya Kepemimpinan Melayani dan Kesiapan untuk Berubah pada Karyawan BPJS Ketenagakerjaan. Jurnal Empati, 5(1), 113-116.

Makena, J. E. (2017). Pengaruh Kepemimpinan Transformasional Terhadap Kinerja Organisasi Melalui Pembelajaran Organisasi dan Inovasi Pada Hotel Prama Sanur Beach Bali. JAGADHITA:Jurnal Ekonomi \& Bisnis, 4(2), 76-88. https://doi.org/10.22225/jj.4.2.135.7 6-88

Mathis, \& Jackson. (2002). Manajemen Sumber Daya Manusia (Pertama). Salemba Empat.

Monoyasa, M. W., Sularso, R. A., \& 
Prihatini, D. (2017). Pengaruh Gaya Kepemimpinan Transformasional Kepala Sekolah Terhadap Kinerja Guru Sekolah Dasardengan Motivasidan Inovasi Guru Sebagai Variabel Intervening Dieks Kota Administratif. JURNAL RELASI STIE MANDALA JEMBER, 13(2), 315-335. http://jurnal.stiemandala.ac.id/index.php/relasi/artic le/download/120/107

Mujiburrahman, Asmony, T., \& Husnan, H. (2017). Pengaruh Kepemimpinan Transformasional Dan Iklim Psikologis Terhadap Kesiapan Untuk Berubah Karyawan Puskesmas Kabupaten Lombok Barat Dalam Rangka Akreditasi Dan Komitmen Afektif Sebagai Variabel Intervening. JURNAL MAGISTER MANAJEMEN, 6(2), 1-19. https://doi.org/JURNAL

\section{MAGISTER MANAJEMEN}

Novitasari, D., Asbari, M., Wijaya, M. R., \& Yuwono, T. (2020). Effect of Organizational Justice on Organizational Commitment: Mediating Role of Intrinsic and Extrinsic Satisfaction. International Journal of Science and Management Studies (IJSMS), 3(3), 96-112. http://www.ijsmsjournal.org/current -issue.html

Nugroho, Y. A., Asbari, M., Purwanto, A., Basuki, S., Sudiyono, R. N., Fikri, M. A. A., Hulu, P., Mustofa, Chidir, G., Suroso, \& Xavir, Y. (2020). Transformational Leadership and Employees' Performance: the Mediating Role of Motivation and Work Environment. EduPsyCouns: Journal of Education, Psychology and Counseling, 2(1), 438-460. https://ummaspul.ejournal.id/Edupsycouns/article/view 1507

Nuryanti, Y., Novitasari, D., Nugroho, Y. A., Fauji, A., Gazali, \& Asbari, M. (2020). Meningkatkan Komitmen Organisasional Dosen: Analisis Pengaruh Kepemimpinan Perguruan
Tinggi dan Kepuasan Intrinsik \& Ekstrinsik Dosen. EduPsyCouns: Journal of Education, Psychology and Counseling, 2(1), 561-581. https://ummaspul.ejournal.id/Edupsycouns/article/view 1551

Pramadani, A. B. (2012). Hubungan antara Komitmen Organisasi dengan Kesiapan untuk Berubah pada Karyawan Divisi Enterprise Service (DES) Telkom Ketintang Surabaya. Jurnal Psikologi Industri Dan Organisasi, 1(03), 112-119.

Purwanto, A., Asbari, M., Budi Santoso, P., Mayesti Wijayanti, L., Chi Hyun, C., Berman Sihite, O., \& Prameswari Saifuddin, M. (2020a). Pengaruh Gaya Kepemimpinan Partisipatif dan Otokratis Terhadap Kinerja Sistem Jaminan Halal HAS 23000 Pada Industri Makanan Kemasan. Edumaspul - Jurnal Pendidikan, 4(1). https://www.researchgate.net/public ation/339470652_Pengaruh_Gaya_ Kepemimpinan_Partisipatif_dan_Ot okratis_Terhadap_Kinerja_Sistem_ Jaminan_Halal_HAS_23000_Pada_ Industri_Makanan_Kemasan

Purwanto, A., Asbari, M., Fahlevi, M., Mufid, A., Agistiawati, E., Cahyono, Y., \& Suryani, P. (2020b). Impact of Work From Home ( WFH ) on Indonesian Teachers Performance During the Covid-19 Pandemic : An Exploratory Study. International Journal of Advanced Science and Technology, 29(5), 6235-6244. http://sersc.org/journals/index.php/I JAST/article/view/15627

Purwanto, A., Asbari, M., \& Hadi, A. H. (2020a). Gaya Kepemimpinan Perguruan Tinggi Kesehatan: Authentic, Tansformational, Authoritarian atau Transactional. Surya Medika Jurnal Ilmiah Ilmu Keperawatan Dan Ilmu Kesehatan Masyarakat, 15(1), 8-18. https://doi.org/10.32504/sm.v15i1.1 63 
Purwanto, A., Asbari, M., \& Hadi, A. H. (2020b). Pengaruh Gaya Kepemimpinan Tansformational, Authentic, Authoritarian, Transactional Terhadap Kinerja Guru Pesantren di Jawa Barat. Dirasah, $3(1)$. https://ejournal.iaifa.ac.id/index.php /dirasah

Purwanto, A., Asbari, M., Prameswari, M., \& Ramdan, M. (2020c). Gaya Kepemimpinan Di Madrasah Aliyah: Authentic, Tansformational, Authoritarian Atau Transactional? Nidhomul Haq, 5, 15-31. https://doi.org/10.31538/ndh.v5i1.5 44

Purwanto, A., Asbari, M., Prameswari, M., Ramdan, M., \& Setiawan, S. (2020d). Dampak Kepemimpinan, Budaya Organisasi dan Perilaku Kerja Inovatif Terhadap Kinerja Pegawai Puskesmas. Jurnal Ilmu Kesehatan Masyarakat, 9(01), 1927.

https://doi.org/10.33221/jikm.v9i01. 473

Purwanto, A., Asbari, M., \& Santoso, P. B. (2019). Influence of Transformational and Transactional Leadership Style toward Food Safety Management System ISO 22000:2018 Performance of Food Industry in Pati Central Java. Inovbiz: Jurnal Inovasi Bisnis, 7(2), 180-185.

https://doi.org/10.35314/inovbiz.v7i 2.1213

Purwanto, A., Bernarto, I., Asbari, M., Mayesti Wijayanti, L., \& Chi Hyun, C. (2020e). Effect of Transformational and Transactional Leadership Style on Public Health Centre Performance. Journal of Reseacrh in Business, Economics, and Education, 2(1), 304-314. http://e-journal.stie-

kusumanegara.ac.id

Purwanto, A., Mayesti Wijayanti, L., Chi Hyun, C., \& Asbari, M. (2019). the
Effect of Tansformational, Transactional, Authentic and Authoritarian Leadership Style Toward Lecture Performance of Private University in Jawa Barat. DIJDBM, 1(1), 29-42. https://doi.org/10.31933/DIJDBM

Purwanto, A., Pramono, R., Asbari, M., Santoso, P. B., Wijayanti, L. M., Choi, C. H., \& Putri, R. S. (2020f). Studi Eksploratif Dampak Pandemi COVID-19 Terhadap Proses Pembelajaran Online di Sekolah Dasar. EduPsyCouns: Journal of Education, Psychology and Counseling, 2(1), 1-12. https://ummaspul.ejournal.id/Edupsycouns/article/view 1397

Purwanto, A., Pramono, R., Asbari, M., Senjaya, P., Hadi, A. H., \& Andriyani, Y. (2020g). Pengaruh Kepemimpinan terhadap Kinerja Guru Sekolah Dasar dengan Keterlibatan Kerja dan Budaya Organisasi sebagai Mediator.

EduPsyCouns: Journal of Education, Psychology and Counseling, 2(1), 50-63. https://ummaspul.ejournal.id/Edupsycouns/article/view 1412

Purwanto, A., Wijayanti, L. M., Choi, C. H., \& Asbari, M. (2019). the Effect of Tansformational, Transactional, Authentic and Authoritarian Leadership Style Toward Lecture Performance of Private University in Jawa Barat. DIJDBM, 1(1), 29-42. https://doi.org/10.31933/DIJDBM

Putri, M. D., \& Soedarsono, D. K. (2017). Pengaruh Kepemimpinan Transformasional Dan Employee Engagement Terhadap Kinerja Karyawan Direktorat Solution Operation Telkomsigma. $E$ Proceeding of Management:, 4(3), 2541-2546.

Robbins, S. P. (2001). Organizational Behavior: Concept, Controversies, 
Aplications (8th Editio). Indeks Kelompok Gramedia.

Sari, P. O. (2018). Pengaruh Gaya Kepemimpinan Transformasional, Komitmen Afektif, Komitmen Kontinuans dan Komitmen Normatif terhadap Kesiapan Berubah (Studi Pada Bank BRI Kantor Wilayah Yogyakarta). EXERO: Journal of Research in Business and Economics, $\quad 1(1), \quad 68-89$. https://doi.org/10.24071/exero.2018 .010104

Setyowati Putri, R., Purwanto, A., Pramono, R., Asbari, M., Mayesti Wijayanti, L., \& Chi Hyun, C. (2020). Impact of the COVID-19 Pandemic on Online Home Learning: An Explorative Study of Primary Schools in Indonesia. International Journal of Advanced Science and Technology, 29(5), 4809-4818.

http://sersc.org/journals/index.php/I JAST/article/view/13867

Siswatiningsih, I., Raharjo, K., \& Prasetya, A. (2019). Pengaruh Kepemimpinan Transformasional Dan Transaksional Terhadap Budaya Organisasi, Motivasi Kerja, Komitmen Oganisasional Dan Kinerja Karyawan. Jurnal Bisnis Dan Manajemen, 5(2), 146-157. https://doi.org/10.26905/jbm.v5i2.2 388

Sopa, A., Asbari, M., Purwanto, A., Budi Santoso, P., Mustofa, Hutagalung, D., Maesaroh, S., Ramdan, M., \& Primahendra, R. (2020a). Hard skills versus soft skills: Which are more important for indonesian employees innovation capability. International Journal of Control and Automation, 13(2), 156-175. http://sersc.org/journals/index.php/I JCA/article/view/7626

Sopa, A., Asbari, M., Purwanto, A., Budi Santoso, P., Mustofa, Hutagalung, D., Maesaroh, S., Ramdan, M., \& Primahendra, R. (2020b). Hard skills versus soft skills: Which are more important for indonesian employees innovation capability. International Journal of Advanced Science and Technology, 29(3), 6431-6453. http://sersc.org/journals/index.php/I JAST/article/view/7233

Sudiyono, R. N., Fikri, M. A. A., Asbari, M., Suroso, Nugroho, Y. A., \& Singgih, E. (2020). The Role of Employee Engagement in the Relationship between Authentic Leadership , Talent Management and Job Satisfaction. International Journal of Advanced Science and Technology, 29(5), 11809-11836. http://sersc.org/journals/index.php/I JAST/article/view/25377

Susyanto, H. (2019). Pengaruh Kepemimpinan, Keterlibatan Karyawan dan Kepuasan Kerja terhadap Kesiapan untuk Berubah dalam Menghadapi Perubahan Organisasi. Jurnal Ekonomi, Bisnis, Dan Akuntansi (JEBA), 21(1).

Waruwu, H., Asbari, M., Purwanto, A., Nugroho, Y. A., Fikri, M. A. A., Fauji, A., Shobihi, A. W. I., Hulu, P., Sudiyono, R. N., Agistiawati, E., \& Dewi, W. R. (2020). The Role of Transformational Leadership, Organizational Learning and Structure on Innovation Capacity: Evidence from Indonesian Private Schools. EduPsyCouns: Journal of Education, Psychology and Counseling, 2(1), 378-397. https://ummaspul.e-

journal.id/Edupsycouns/article/view 1499

Yanthy, E., Purwanto, A., Pramono, R., Cahyono, Y., \& Asbari, M. (2020). Pengaruh Gaya Kepemimpinan Transformasional dan Tranksaksional Terhadap Kinerja Sistem Jaminan Halal HAS 23000. Jurnal Bisnis Dan Manajemen Islam, $\quad 8(1)$. https://doi.org/http://dx.doi.org/10.2 1043/bisnis.v8i1.7045 
Yuwono, T., Novitasari, D., Hutagalung, D., Sasono, I., Silitonga, N., \& Asbari, M. (2020). Peran Organizational Justice terhadap Komitmen Organisasional: Analisis Mediasi Kepuasan Kerja Dosen Perguruan Tinggi Swasta. EduPsyCouns: Journal of Education, Psychology and Counseling, 2(1), 582-599. https://ummaspul.ejournal.id/Edupsycouns/article/view 1550 